\title{
Early and intermediate Amadori glycosylation adducts, oxidative stress, and endothelial dysfunction in the streptozotocin-induced diabetic rats vasculature
}

\author{
L. Rodríguez-Mañas ${ }^{1}$, J. Angulo ${ }^{1}$, S. Vallejoํㅜ C. Peiró ${ }^{2}$, A. Sánchez-Ferrer ${ }^{1}$, E. Cercas ${ }^{2}$, P. López-Dóriga ${ }^{1}$, \\ C. F. Sánchez-Ferrer ${ }^{2}$ \\ ${ }^{1}$ Research Unit and Service of Geriatrics, University Hospital of Getafe, Madrid, Spain \\ 2 Department of Pharmacology and Therapeutics, Faculty of Medicine, Autonomous University of Madrid, Madrid, Spain
}

\begin{abstract}
Aims/hypothesis. In a model of streptozotocin-induced Type 1 diabetes mellitus in rats of 9 weeks duration, we analysed time associations between the development of hyperglycaemia, early and intermediate glycosylation Amadori adducts, or AGE compared with enhancement of oxidative stress and endothelial dysfunction.

Methods. Endothelial function was tested at several stages of streptozotocin-induced diabetes and after treatment with insulin, resulting in different concentrations of blood glucose, glycosylated haemoglobin (an Amadori adduct), and AGE. Other animals were studied antagonising the formation of AGE with aminoguanidine.

Results. Relaxation in response to acetylcholine ( $1 \mathrm{nmol} / \mathrm{l}$ to $10 \mu \mathrm{mol} / \mathrm{l}$ ) was tested in isolated segments from aorta or mesenteric microvessels. Impairment of endothelium-dependent relaxations occurred after 2 weeks of untreated diabetes. Preincubation of vessels affected with $100 \mathrm{U} / \mathrm{ml}$ superoxide dismutase
\end{abstract}

improved the relaxations to acetylcholine, along the time-course of the endothelial impairment. This indicates the participation of reactive oxygen species on diabetic endothelial dysfunction. The impairment of endothelium-dependent relaxations was recovered after 3 more weeks of insulin treatment. Aminoguanidine treatment did not modify this pattern of development. The time course of the rise and disappearance of endothelial dysfunction showed a higher correlation with glycosylated haemoglobin concentrations than with blood glucose or serum AGE.

Conclusion/interpretation. Enhancement of early and intermediate Amadori adducts of protein glycosylation was the factor showing a better relation with the development of endothelium impairment. These results are consistent with a role for these products in the development of diabetic vasculopathy. [Diabetologia (2003) 46:556-566]

Keywords Diabetes mellitus, endothelial dysfunction, nitric oxide, superoxide anions, hyperglycaemia, Amadori adducts, advanced glycosylation end-products.
Received: 1 March 2002 / Revised: 7 November 2002

Published online: 12 March 2003

C Springer-Verlag 2003

Corresponding author: Dr. C. F. Sánchez-Ferrer, Department of Pharmacology and Therapeutics, Faculty of Medicine, Autonomous University of Madrid, c/Arzobispo Morcillo 4, 28029 Madrid, Spain

E-mail: carlosf.sanchezferrer@uam.es

Abbreviations: ACh, acetylcholine; NA, noradrenaline; KHS, Krebs-Henseleit solution; KKHS, equimolar substitution of $\mathrm{KCl}$ for $\mathrm{NaCl}$ in $\mathrm{KHS}$; ROS, reactive oxygen species; SOD, superoxide dismutase.
Endothelial dysfunction seems to be a key factor in the development of diabetic vascular complications. The impairment of endothelium-dependent vasodilatations is an early event occurring in diabetic patients $[1,2,3]$ and animal diabetic models [4, 5, 6, 7]. Enhanced oxidative stress in diabetes mellitus has been also shown $[8,9]$, which can be detected by peroxidation products [10] or by increased generation of reactive oxygen species (ROS), mainly superoxide anions [11]. Indeed, enhanced oxidative stress is proposed to be a major cause of diabetic endothelial dysfunction $[12,13]$.

There is also increasing evidence that diabetic endothelial dysfunction and oxidative stress are a conse- 
quence of hyperglycaemia $[13,14]$, as the control of blood glucose is essential for the prevention of diabetic vascular complications $[15,16,17]$. However, the specific mechanisms linking hyperglycaemia with oxidative stress and endothelial dysfunction are not well understood. Some authors suggest that increased blood glucose concentrations directly produce oxidative stress and endothelium impairment [18, 19, 20, 21, 22, $23,24]$. Other investigators propose that hyperglycaemia can modify different enzymatic pathways, which produce oxidative stress and cause the alterations of endothelium. Aldose reductase, protein kinase C, endothelin receptors, and poly(ADP-ribose) polymerase are among the mechanisms suggested [25, 26, 27, 28].

In contrast, an important role has been proposed for non-enzymatic protein glycosylation, a process that is related to glucose concentration and duration of hyperglycaemia. Different products are formed during the process of protein glycosylation. The terminal adducts of non-enzymatic glycosylation of proteins, called advanced glycosylation end-products, induce oxidant stress, quenching nitric oxide and producing alterations of endothelial function $[29,30,31]$. However, early and intermediate products of non-enzymatic protein glycosylation (Amadori adducts) can also be involved in diabetic endothelial dysfunction. Highly glycosylated oxyhaemoglobin, a typical Amadori adduct [32], impairs endothelium-dependent relaxations through the release of superoxide anions [33, $34,35]$. In streptozotocin-induced diabetic rats, a clear correlation exists between the blood concentrations of $\mathrm{HbA}_{1 \mathrm{c}}$ and the development of endothelial dysfunction [36, 37]. Furthermore, in Type 1 diabetic patients, the blood concentrations of Amadori albumin clearly correlate with some markers of endothelial function, nephropathy, and retinopathy [38].

The study of the possible mechanisms producing oxidative stress-induced endothelial dysfunction in diabetes also requires assessing the time course correlation between vascular dysfunction and the proposed mechanism. Therefore, we studied a model of early Type 1 diabetes (9-week streptozotocin-induced diabetic rats), analysing the time associations between the development of oxidative stress and endothelial dysfunction with the presence of hyperglycaemia, high blood $\mathrm{HbA}_{1 \mathrm{c}}$, or enhanced serum AGE concentrations. Thus, the endothelial function was tested at several stages of evolution since the disease was induced and after additional treatment with insulin, leading to different concentrations of blood glucose, $\mathrm{HbA}_{1 \mathrm{c}}$ and AGE. Furthermore, in some animals the formation of AGE was antagonised with aminoguanidine.

\section{Subjects and methods}

This work was carried out according to the European regulations. The study was approved by the Local Committee of Research.
Experimental animals. Insulin-dependent diabetes was induced in 16-week-old male Sprague-Dawley rats (400 to $450 \mathrm{~g}$ ) by a single administration of streptozotocin (i.p. $60 \mathrm{mg} \cdot \mathrm{kg}^{-1}$ ) dissolved in citric acid-trisodium citrate $(0.1 \mathrm{mmol} / \mathrm{l})$ buffer with a pH of 4.5. After $72 \mathrm{~h}$, tail blood samples were obtained and glucose concentration was measured using a glucometer Accutrend (Boehringer Mannheim, Mannheim, Germany). Diabetes induction was considered successful when glycaemia was higher than $20 \mathrm{mmol} / \mathrm{l}$. A group of rats were injected with saline solution and kept in identical conditions as control nondiabetic animals.

According to different time schedule and insulin treatment, experimental animals were separated into several groups of rats: Week 0 , untreated non-diabetic rats $(n=23)$; Week 1 , untreated diabetic rats with 1 week of evolution $(n=5)$; Week 2 , untreated diabetic rats with 2 weeks of evolution $(n=5)$; Week 3 , untreated diabetic rats with 3 weeks of evolution $(n=10)$; Week 6, untreated diabetic rats with 6 weeks of evolution $(n=21)$; Week 7, diabetic rats untreated for 6 weeks with an additional treatment with insulin during 1 week $(n=5)$; Week 9 , diabetic rats untreated for 6 weeks with an additional treatment with insulin during 3 weeks $(n=11)$. Aminoguanidine-treated rats were also divided into different groups, depending on time and insulin administration: Week 0 , non-diabetic rats treated with aminoguanidine for 9 weeks $(n=14)$; Week 6 , diabetic rats with 6 weeks of evolution treated with aminoguanidine $(n=17)$; Week 7, aminoguanidine-treated diabetic rats with 6 weeks of evolution and 1 additional week treated with insulin $(n=5)$; Week 9, aminoguanidine-treated diabetic rats with 6 weeks of evoluti0on and 3 additional weeks treated with insulin $(n=11)$.

Insulin (12 U. $\left.\mathrm{kg}^{-1} \cdot \mathrm{day}^{-1}\right)$ was administered by subcutaneous implants of bovine insulin (Linplant, Scarborough, Ontario, Canada). These implants contain palmitic acid as vehicle and were introduced without sutures under the dorsal skin of the rats slightly anaesthetized with Ketolar $\left(30 \mathrm{mg} \cdot \mathrm{kg}^{-1}\right.$, i.p.). Every implant gradually releases the insulin, at a dose of two units a day. Non-diabetic and untreated diabetic rats received control implants of palmitic acid (Linplant). Aminoguanidine $\left(250 \mathrm{mg} \cdot \mathrm{kg}^{-1} \cdot \mathrm{day}^{-1}\right)$ was added to drinking water.

Analytical determinations. At the time of the experiment, blood glucose concentrations, blood $\mathrm{HbA}_{1 \mathrm{c}}$, and serum concentrations of AGE were systematically determined. In some cases, tissular concentrations of AGE were also measured in aortic vascular wall homogenates. $\mathrm{HbA}_{1 \mathrm{c}}$ was measured by immunoturbidimetric assay [39]. Measurements of AGE were done according to a previously described protocol [40] using polyclonal antiserum to AGE epitopes, which were formed in vitro after the incubation of bovine pancreatic ribonuclease in the presence of $0.5 \mathrm{~mol} / \mathrm{l}$ glucose for 60 days. This antiserum was obtained from female New Zealand white rabbits receiving four primary and one booster immunisation of ribonuclease or AGE-ribonuclease emulsified in Freund's complete adjuvant [40]. The AGE-antiserum was kindly provided by Dr. R. Bucala (Rockefeller University, New York, NY, USA). Antibody response was monitored by ELISA (EL-340, Bio-Tek Instruments, Winooski, $\mathrm{V})$. The content of AGE was calculated by using AGE from bovine sero-albumin as a standard antigen. Increasing concentrations of bovine sero-albumin-AGE (0.001 to $0.1 \mathrm{mg} / \mathrm{ml}$ ) were used to establish a standard curve of antibody binding to the antigen. The semilogarithmic transformation of these data yielded a regression line with a $r^{2}=0.985$. Results of serum AGE were therefore expressed as equivalents of bovine sero-albumin AGE per $\mathrm{mg}$ of serum protein (U/mg protein).

Drug effects on vascular tone of aortic isolated rings. Rats were anaesthetised with $70 \mathrm{mg} \cdot \mathrm{kg}^{-1}$ i.p. sodium pentobarbital and 
killed by bleeding. The aorta was carefully dissected, cleaned of excess fat and connective tissue, placed in a Petri dish containing Krebs-Henseleit solution (KHS) at $4^{\circ} \mathrm{C}$, and divided into cylindrical segments of 4 to $5 \mathrm{~mm}$ in length. For isometric tension recording, each vascular cylinder was set up in an organ bath according to a method described previously [33]. The organ chamber contained $5 \mathrm{ml}$ of $\mathrm{KHS}$ at $37^{\circ} \mathrm{C}$ continuously bubbled with a $95 \% \mathrm{O}_{2}$ and $5 \% \mathrm{CO}_{2}$ mixture, which gave a $\mathrm{pH}$ of 7.4. Two horizontally arranged stainless steel pins were passed through the lumen of the vascular cylinder. One pin was fixed to the organ bath wall while the other one was connected vertically to a strain gauge for isometric tension recording. The isometric contraction was recorded through a force-displacement transducer (Grass FTO3C; Quincy, Mass. USA) connected to a Grass model 7D polygraph. The segments were subjected to a tension of $1.5 \mathrm{~g}$ (optimal resting tension, at which maximal contractile responses to $\mathrm{K}^{+}$were obtained), which was readjusted every 15 min during a 90 min equilibration period before the drug was added.

At the beginning of the experiment, the vessels were exposed to $75 \mathrm{mmol} / 1 \mathrm{~K}^{+}$to check their functional integrity. After a washout period, each segment was contracted with the concentration of noradrenaline (NA, 10 to $30 \mathrm{nmol} / \mathrm{l}$ ) required to induce a contractile response equivalent to 55 to $65 \%$ of that induced by $\mathrm{K}^{+}$. Once a stable plateau was reached, concentration-response curves to $\mathrm{ACh}(10 \mathrm{nmol} / \mathrm{l}$ to $10 \mu \mathrm{mol} / \mathrm{l})$ were carried out. Segments with relaxant responses to $10 \mu \mathrm{mol} / \mathrm{l} \mathrm{ACh}$ greater than $50 \%$ of the precontraction were considered to have an intact endothelium [34]. In some cases, the curve to ACh was done after incubating the segments for 15 min with superoxide dismutase (SOD; $100 \mathrm{U} / \mathrm{ml}$ ). Removal of endothelium with saponin $\left(0.3 \mathrm{mg} \mathrm{ml}-1\right.$ in $\mathrm{KHS}$ oxygenated at $\left.37^{\circ} \mathrm{C}\right)$ for $15 \mathrm{~min}$ [33] abolished relaxations to ACh. In other experiments, concentration-dependent curves to sodium nitroprusside (SNP; $10 \mathrm{nmol} / 1$ to $10 \mu \mathrm{mol} / \mathrm{l}$ ) were also carried out.

Drug effects on vascular tone of mesenteric microvessels. The mesentery was removed and placed in KHS. The third branch mesenteric arteries were dissected in control and diabetic rats (mean internal diameter ranged between 200 and $400 \mu \mathrm{m}$; nonsignificant differences were observed among the different groups of rats). The arteries were dissected free of connective tissue under a light microscope and mounted as ring preparations on a small vessel myograph [41] capable of measuring isometric tension. Arteries were bathed in KHS at $37^{\circ} \mathrm{C}$ continuously bubbled with a $95 \% \mathrm{O}_{2}$ and $5 \% \mathrm{CO}_{2}$ mixture and their passive tension and internal circumference were measured. The arteries were then set to an internal circumference equivalent to $90 \%$ of that which they would experience when relaxed in situ under a transmural pressure of $100 \mathrm{mmHg}$ [41]. Arteries were then contracted with $125 \mathrm{mmol} / \mathrm{l} \mathrm{K} \mathrm{K}^{+}$(KKHS, equimolar substitution of $\mathrm{KCl}$ for $\mathrm{NaCl}$ in $\mathrm{KHS}$ ) for $2 \mathrm{~min}$. Segments failing to produce a maximum active tension equivalent to a pressure of $100 \mathrm{mmHg}$ on the final contraction were rejected [36].

The bath was then washed three times with KHS and a further $30 \mathrm{~min}$ washout period was allowed before the arteries were contracted with the concentration of NA ( 1 to $2 \mu \mathrm{mol} / \mathrm{l})$ required to produce approximately $80 \%$ of the maximum response to KKHS. Relaxation to ACh was subsequently assessed by adding increasing concentrations of the drugs at 2 min intervals (final bath concentrations $1 \mathrm{nmol} / \mathrm{l}$ to $10 \mu \mathrm{mol} / \mathrm{l})$. In some cases, the curve to ACh was done after incubating the segments for $15 \mathrm{~min}$ with SOD $(100 \mathrm{U} / \mathrm{ml})$. In other experiments, concentration-dependent curves to SNP ( $10 \mathrm{nmol} / \mathrm{l}$ to $10 \mu \mathrm{mol} / \mathrm{l}$ ) were also carried out.

Drugs used. The composition of KHS (mmol/l) was $\mathrm{NaCl} 115$, $\mathrm{CaCl}_{2} 25, \mathrm{KCl} 4.6, \mathrm{KH}_{2} \mathrm{PO}_{4} 1.2, \mathrm{MgSO}_{4} \cdot 7 \mathrm{H}_{2} \mathrm{O} 1.2, \mathrm{NaHCO}_{3}$

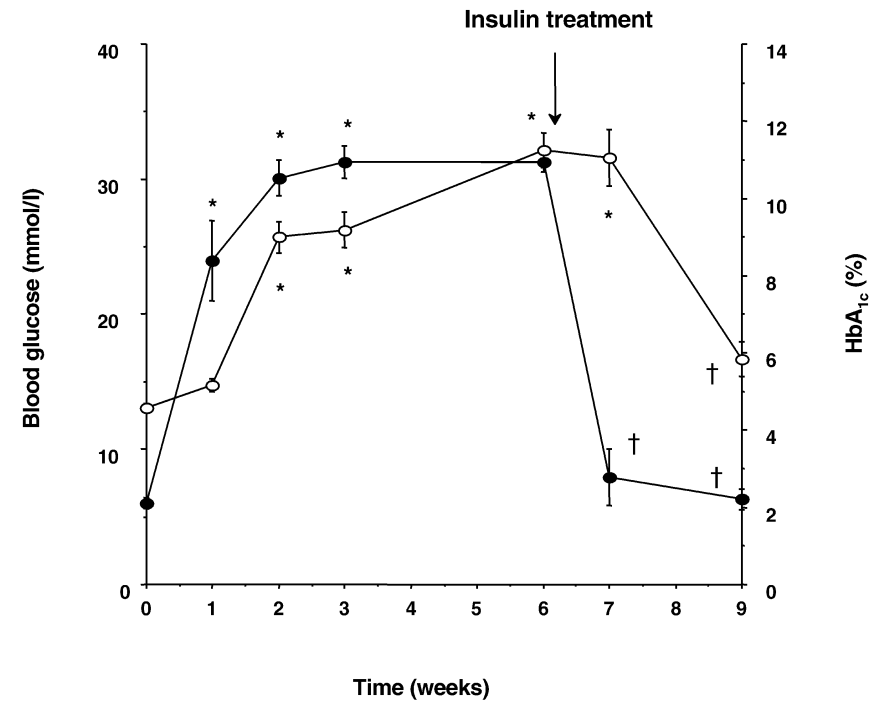

Fig. 1. Blood concentrations of glucose $(\bigcirc)$ and $\mathrm{HbA}_{1 \mathrm{c}}(\bigcirc)$ during 9 weeks after induction of diabetes in Sprague-Dawley rats. In the $6^{\text {th }}$ week, insulin implants were introduced $\left(12 \mathrm{U} \cdot \mathrm{Kg}^{-1} \cdot \mathrm{day}^{-1}\right)$. Data are means \pm SEM. ${ }^{*} p<0.001$ vs Week $0 ; \uparrow p<0.001$ vs Week 6

25, glucose 11.1 and $\mathrm{Na}_{2}$ EDTA 0.03 . Drugs used were NA hydrochloride, ACh chloride, aminoguanidine, and $\mathrm{CuZn}$ superoxide dismutase (EC 1.15.1.1) from bovine erythrocytes (all of them from Sigma, St Louis, Mo. USA). Drug solutions were made in distilled water except noradrenaline, which was prepared in saline $(0.9 \% \mathrm{NaCl})$-ascorbic acid $(0.01 \% \mathrm{w} / \mathrm{v})$.

Statistical evaluation. Deviations from the mean regarding the curves to ACh were statistically analysed using factorial twoway ANOVA. Stepwise regressions were used to analyse the relation between blood glucose, $\mathrm{HbA}_{1 \mathrm{c}}$, values, and those of AGE with $\mathrm{pD}_{2}$ values for $\mathrm{ACh}$, this later one defined as the negative $\log$ of the effective dose required to produce half the maximum effect. Student's $t$ test was used in the statistical comparison of $\mathrm{pD}_{2}$ values (mean $\pm \mathrm{SE}$ ). $P$ values were adjusted with Bonferroni correction for multiple comparisons. Significance was considered at a $p$ value of less than 0.05 .

\section{Results}

The evolution of glycaemia and blood $\mathrm{HbA}_{1 \mathrm{c}}$ concentrations during 9 weeks of development after induction of diabetes in Sprague-Dawley rats is shown (Fig. 1). The animals were treated with insulin since week 6 to week 9. The changes in $\mathrm{HbA}_{1 \mathrm{c}}$ values were produced at least 1 week later than the respective modifications of blood glucose. The values of serum AGE in these groups of rats are shown (Fig. 2), together with those of corresponding groups of animals receiving $250 \mathrm{mg} / \mathrm{kg}$ aminoguanidine in drinking water. Serum AGE enhanced in a time-dependent manner during the 6 weeks of evolution of untreated diabetes. After 3 additional weeks of insulin treatment there was no significant reduction in serum AGE. The formation of serum AGE, however, was markedly impaired when the animals received aminoguanidine 


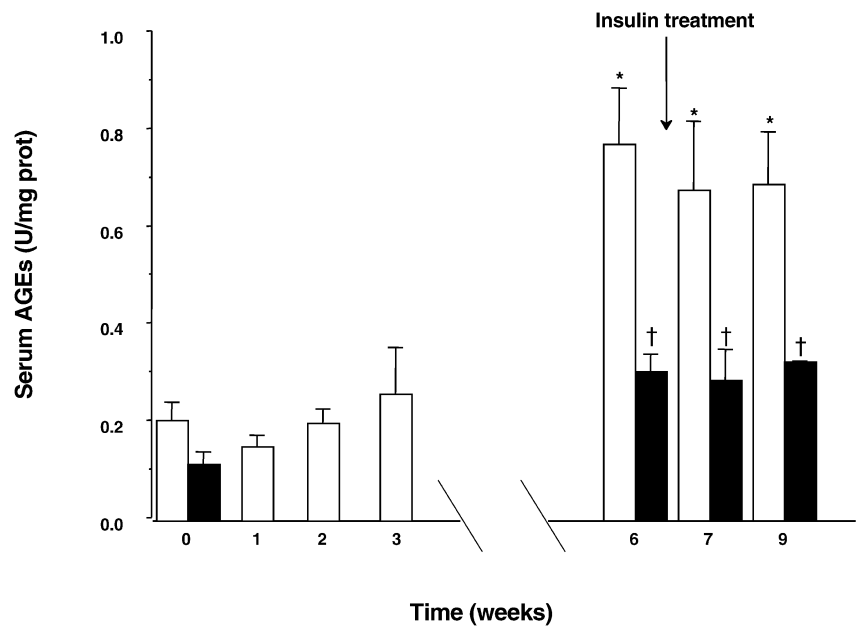

Fig. 2. Serum concentrations of AGE, in the absence $(\square)$ or in the presence $(\mathbf{\square})$ of $250 \mathrm{mg} / \mathrm{Kg}$ aminoguanidine in SpragueDawley rats. In the $6^{\text {th }}$ week, insulin implants were introduced $\left(12 \mathrm{U} \cdot \mathrm{Kg}^{-1} \cdot \mathrm{day}^{-1}\right) * p<0.001$ vs Week $0 ; \dagger p<0.001$ from the respective group not receiving aminoguanidine. $U$ means units of serum AGEs expressed as equivalents of bovine sero-albumin AGE
(Fig. 2). The values of glycaemia and $\mathrm{HbA}_{1 \mathrm{c}}$ in aminoguanidine-treated groups were similar to those obtained in the analogous groups not receiving the drug (Table 1).

The concentration of tissular AGE was measured in aortic wall homogenates from rats of several groups with and without treatment with aminoguanidine. In rats not receiving the drug, the obtained values were $1.56 \pm 0.89,1.65 \pm 0.60$, and $1.83 \pm 0.83 \mathrm{U} / \mathrm{mg}$ protein, respectively, for the Week 0 , Week 3, and Week 6 groups (NS differences). In rats treated with aminoguanidine, tissular AGE were $0.43 \pm 0.12$ and $0.71 \pm 0.15 / \mathrm{mg}$ protein, respectively, for the Week 0 and Week 6 groups (NS differences).

Isolated segments of aorta and mesenteric microvessels obtained from the different animal groups were contracted with 10 to $30 \mathrm{nmol} / \mathrm{l}$ and 1 to $2 \mu \mathrm{mol} / \mathrm{l}$ NA, respectively. The contractile responses obtained were similar in vessels from the different groups, either with or without aminoguanidine treatment (Table 2). The preincubation of the vessels with $100 \mathrm{U} / \mathrm{ml}$ SOD did not alter the NA-evoked responses in any of the groups (Table 2).

Table 1. Values of blood glucose and $\mathrm{HbA}_{1 \mathrm{c}}$ in non-diabetic and streptozotocin-induced diabetic rats treated with aminoguanidine

\begin{tabular}{|c|c|c|c|}
\hline Weeks & Intervention & Glycaemia (mmol/l) & $\mathrm{HbA}_{1 \mathrm{c}}(\%)$ \\
\hline 0 & Untreated non-diabetic with aminoguanidine & $5.05 \pm 0.20(14)$ & $4.23 \pm 0.07(14)$ \\
\hline 6 & 6 weeks of diabetes with aminoguanidine & $30.16 \pm 1.07 \mathrm{~b}(17)$ & $10.28 \pm 0.61 \mathrm{~b}(17)$ \\
\hline 9 & 6 weeks of diabetes with aminoguanidine plus 3 week of treatment with insulin & $6.86 \pm 0.83(11)$ & $7.02 \pm 0.45$ a $(11)$ \\
\hline
\end{tabular}

Results are means \pm SEM. Number of determinations are in parenthesis.

${ }^{\mathrm{a}} p<0.05$ and ${ }^{\mathrm{b}} p<0.001$ vs Week 0 .

Table 2. Contractions induced by noradrenaline in isolated vessels from non-diabetic and streptozotocin-induced diabetic rats. Effects of superoxide dismutase (SOD)

\begin{tabular}{|c|c|c|c|c|c|}
\hline \multirow[t]{2}{*}{ Weeks } & \multirow[t]{2}{*}{ Intervention } & \multicolumn{2}{|l|}{ Aorta (mg) } & \multicolumn{2}{|c|}{ Mesenteric microvessels (mNewtons) } \\
\hline & & & SOD & & SOD \\
\hline 0 & Untreated non-diabetic with aminoguanidine & $1465 \pm 39(14)$ & $1430 \pm 81(5)$ & $9.01 \pm 0.36(14)$ & $9.74 \pm 0.56(6)$ \\
\hline 1 & 1 week of untreated diabetes & $1470 \pm 114(5)$ & $1342 \pm 84(4)$ & $10.41 \pm 1.36(5)$ & $10.46 \pm 0.94(4)$ \\
\hline 2 & 2 weeks of untreated diabetes & $1361 \pm 155(5)$ & $1312 \pm 130(4)$ & $12.18 \pm 1.22(5)$ & $11.52 \pm 1.09$ \\
\hline 6 & 6 weeks of diabetes with aminoguanidine & $1434 \pm 37(17)$ & $1571 \pm 73(6)$ & $10.87 \pm 0.39(17)$ & $10.61 \pm 1.33(5)$ \\
\hline 7 & $\begin{array}{l}6 \text { weeks of untreated diabetes plus } 1 \text { week } \\
\text { of treatment with insulin }\end{array}$ & $1556 \pm 22(5)$ & $1394 \pm 40(4)$ & $10.65 \pm 1.26(5)$ & $9,91 \pm 0.94(4)$ \\
\hline 7 & $\begin{array}{l}6 \text { weeks of diabetes with aminoguanidine } \\
\text { plus } 1 \text { week of treatment with insulin }\end{array}$ & $1625 \pm 72(5)$ & $1575 \pm 76(4)$ & $10.81 \pm 1.22(5)$ & $12.17 \pm 0.37(4)$ \\
\hline 9 & $\begin{array}{l}6 \text { weeks of untreated diabetes plus } 3 \text { weeks } \\
\text { of treatment with insulin }\end{array}$ & $1415 \pm 44(11)$ & $1386 \pm 46(4)$ & $10.97 \pm 0.90$ & $11.07 \pm 0.73(4)$ \\
\hline
\end{tabular}

Results are means \pm SEM of the averaged contractile responses corresponding to every animal. The respective number of rats is in parenthesis 
Table 3. Values of $\mathrm{pD}_{2}$ for acetylcholine in isolated vessels from non-diabetic and streptozotocin-induced diabetic rats. Effects of superoxide dismutase (SOD)

\begin{tabular}{|c|c|c|c|c|c|}
\hline \multirow[t]{2}{*}{ Weeks } & \multirow[t]{2}{*}{ Intervention } & \multicolumn{2}{|l|}{ Aorta } & \multicolumn{2}{|c|}{ Mesenteric microvessels } \\
\hline & & & SOD & & SOD \\
\hline 1 & 1 week of untreated diabetes & $7.49 \pm 0.05(5)$ & $7.56 \pm 0.03(4)$ & $7.75 \pm 0.13(5)$ & $7.58 \pm 0.25(4)$ \\
\hline 2 & 2 weeks of untreated diabetes & $7.05 \pm 0.12$ a $(5)$ & $7.39 \pm 0.08 \mathrm{c}(4)$ & $6.71 \pm 0.09 \mathrm{~b}(5)$ & $7.02 \pm 0.08$ a \\
\hline 3 & 3 weeks of untreated diabetes & $7.04 \pm 0.03$ b $(5)$ & $7.35 \pm 0.06^{\mathrm{c}}(4)$ & $6.73 \pm 0.23$ b $(5)$ & $6.96 \pm 0.23$ a (4) \\
\hline 9 & $\begin{array}{l}6 \text { weeks of untreated diabetes plus } \\
3 \text { weeks of treatment with insulin }\end{array}$ & $7.34 \pm 0.05(6)$ & $7.34 \pm 0.06(4)$ & $7.77 \pm 0.12(6)$ & $7.85 \pm 0.26(4)$ \\
\hline
\end{tabular}

$\mathrm{pD}_{2}$ indicates the $-\log \mathrm{mol} / \mathrm{l}$ of the required concentration of acetylcholine to reach the half-maximal relaxation. Results are means \pm SEM of the averaged $\mathrm{pD}_{2}$ corresponding to every animal. The respective number of rats is in parenthesis. a $p<0.05$ and ${ }^{\mathrm{b}} p<0.001$ vs Week 0 .

${ }^{c} p<0.05$ and ${ }^{\mathrm{d}} p<0.001$ vs value of respective group without SOD

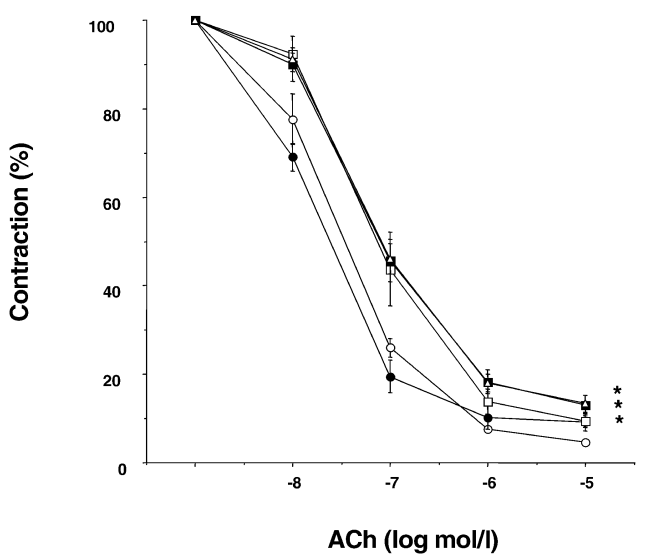

Fig. 3. Relaxant responses to acetylcholine (ACh) in aortic segments (left) and mesenteric microvessels (right) from rats with different stages of diabetes: Week $0,(\bigcirc)$; Week 1, (O); Week 2, $(\square)$; Week 3, $(\square)$; Week 6, $(\triangle)$. The responses are expressed as the percentage of a previous contraction elicited by noradrenaline. The values of these previous contractions and the number of rats used for every curve are in Tables 2 and 3. $* p<0.001$ vs Week 0

The administration of $\mathrm{ACh}$ on pre-contracted isolated vascular segments produced concentrationdependent relaxations in aorta and mesenteric microvessels. In the vascular segments from non-diabetic rats, these relaxant responses did not change among those animals aged between 16 to 25 weeks. In addition, the vasodilatations to $\mathrm{ACh}$ in vessels form nondiabetic rats (Week 0) were not affected by preincubating the tissues with $100 \mathrm{U} / \mathrm{ml}$ SOD (Table 3).

The evolution of endothelium-dependent relaxations during 6 weeks of untreated diabetes and 3 additional weeks of insulin treatment are shown (Fig. 3, 4 , Table 3). In both types of vascular segments, at least 2 weeks of untreated diabetes evolution were required to obtain a reduction of ACh-induced vasodilatations, although blood glucose was increased from

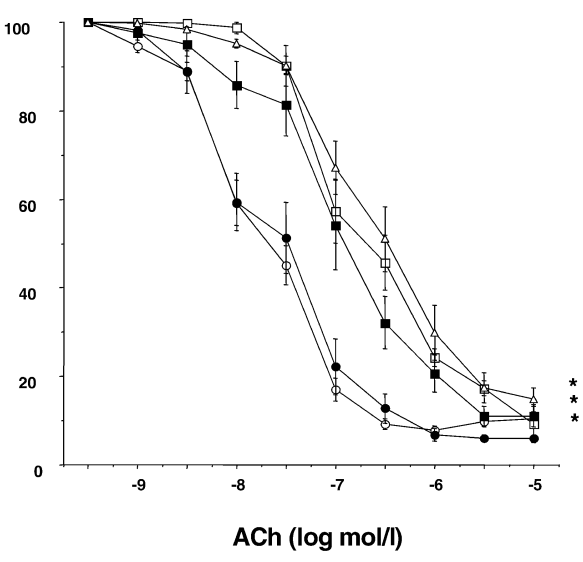

the beginning of the disease (Fig. 3). Analogously, 3 weeks of treatment with insulin were needed to reach a statistical significant recovery of endothelial function (Fig. 4). In aortic segments, preincubation with SOD improved defective ACh-induced responses to values similar to those obtained in non-diabetic rats, while in mesenteric microvessels the recovery of the relaxations by SOD was only partial (Table 3 ).

The evolution of endothelium-mediated responses in rats receiving aminoguanidine in drinking water during the 9 weeks of the experimental protocol are shown (Fig. 5, Table 4). In non-diabetic rats, this drug did not affect ACh-induced relaxations. After 6 weeks of untreated diabetes a statistically significant impairment of these responses were observed, similar to that obtained in vessels from the analogous group not receiving aminoguanidine (Table 4 ). There was also a recovery of endothelial function after insulin treatment (Fig. 5). The responses to $\mathrm{ACh}$ in the presence of SOD were rather similar to those obtained in the respective groups without aminoguanidine in the case of aortic segments, while in mesenteric microvessels SOD failed to improve ACh-induced relaxations (Table 4). 

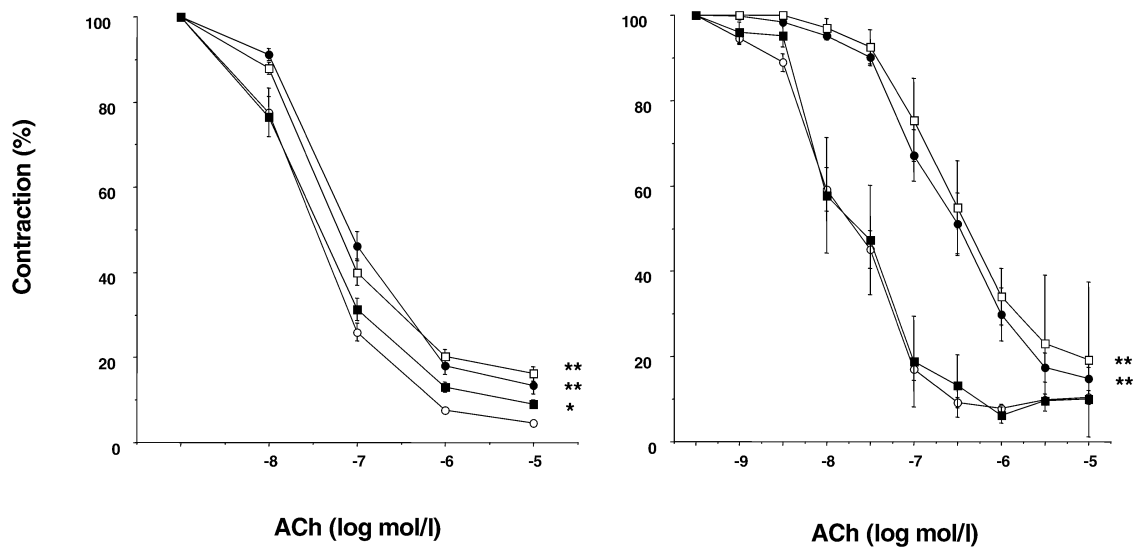

Fig. 4. Relaxant responses to acetylcholine (ACh) in aortic segments (left) and mesenteric microvessels (right) from rats with different stages of diabetes: Week $0,(\bigcirc)$; Week $6,(\bigcirc)$; Week 7, $\square$; Week 9, $(\square)$. The responses are expressed as the

percentage of a previous contraction elicited by noradrenaline. The values of these previous contractions and the number of rats used for every curve are in Tables 2 and $3 .{ }^{*} p<0.05$ and $* * p<0.001$ vs Week 0

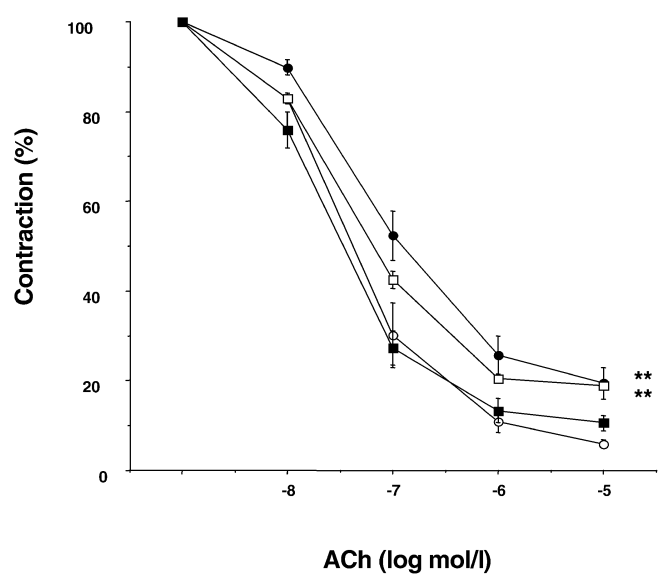

Fig. 5. Relaxant responses to acetylcholine (ACh) in aortic segments (left) and mesenteric microvessels (right) from rats receiving $250 \mathrm{mg} / \mathrm{Kg}$ aminoguanidine in drinking water 1 week prior to and during the 9 weeks of evolution after induction of diabetes: Week $0,(\bigcirc)$; Week 6, $(\bigcirc)$; Week 7, $\square$ ); Week 9,

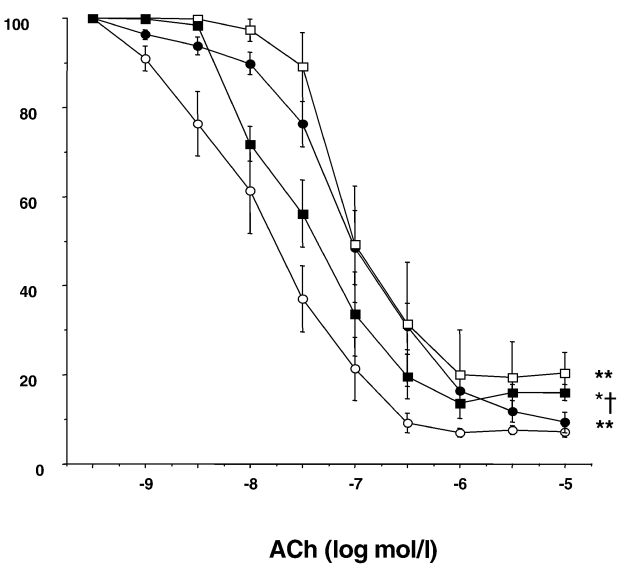

. The responses are expressed as the percentage of a previous contraction elicited by noradrenaline. The values of these previous contractions and the number of rats used for every curve are in Tables 2 and $4 . * p<0.05$ and $* * p<0.001$ vs Week $0 ; \uparrow p<0.001$ vs Week 6

Table 4. Values of $\mathrm{pD}_{2}$ for acetylcholine in vessels from non-diabetic and streptozotocin-induced diabetic rats treated with aminoguanidine. Effects of superoxide dismutase (SOD)

\begin{tabular}{|c|c|c|c|c|c|}
\hline \multirow[t]{2}{*}{ Weeks } & \multirow[t]{2}{*}{ Intervention } & \multicolumn{2}{|l|}{ Aorta } & \multicolumn{2}{|c|}{ Mesenteric microvessels } \\
\hline & & Control & SOD & Control & SOD \\
\hline 6 & 6 weeks of diabetes with aminoguanidine & $6.68 \pm 0.17 \mathrm{~b}(11)$ & $7.40 \pm 0.09 \mathrm{~d}(6)$ & $6.75 \pm 0.12^{\mathrm{b}}(10)$ & $7.12 \pm 0.10^{\mathrm{b}}(6)$ \\
\hline 7 & $\begin{array}{l}6 \text { weeks of diabetes with aminoguanidine } \\
\text { plus } 1 \text { week of treatment with insulin }\end{array}$ & $7.08 \pm 0.09 \mathrm{~b}(5)$ & $7.66 \pm 0.08^{\mathrm{d}}(4)$ & $6.91 \pm 0.14^{b}(5)$ & $6.99 \pm 0.14(4)$ \\
\hline
\end{tabular}

$\mathrm{pD}_{2}$ indicates the $-\log \mathrm{mol} / \mathrm{l}$ of the required concentration of acetylcholine to reach the half-maximal relaxation. Results are means \pm SEM of the averaged $\mathrm{pD}_{2}$ corresponding to every animal. The respective number of rats is in parenthesis. a $p<0.05$ and ${ }^{\mathrm{b}} p<0.001$ vs Week 0.

${ }^{c} p<0.05$ and ${ }^{\mathrm{d}} p<0.01$ vs value of respective group without SOD 
Table 5. Values of $\mathrm{pD}_{2}$ for sodium nitroprusside in segments from non-diabetic and streptozotocin-induced diabetic rats

\begin{tabular}{llll}
\hline Weeks & Intervention & Aorta & Mesenteric microvessels \\
\hline 0 & Untreated non-diabetic & $8.32 \pm 0.25(10)$ & $7.78 \pm 0.07(10)$ \\
0 & Untreated non-diabetic with aminoguanidine & $8.06 \pm 0.25(7)$ & $6.68 \pm 0.23^{\mathrm{a}}(7)$ \\
3 & 3 weeks of untreated diabetes & $8.77 \pm 0.08(5)$ & $7.77 \pm 0.04(5)$ \\
6 & 6 weeks of untreated diabetes & $8.73 \pm 0.04(5)$ & $7.86 \pm 0.13(6)$ \\
6 & 6 weeks of diabetes with aminoguanidine & $8.10 \pm 0.18(6)$ & $6.91 \pm 0.10^{\mathrm{a}(7)}$ \\
9 & 6 weeks of untreated diabetes plus 3 weeks of treatment with insulin & $8.05 \pm 0.14(5)$ & $7.90 \pm 0.06(5)$ \\
9 & 6 weeks of diabetes with aminoguanidine plus 3 week & & $6.85 \pm 0.17^{\mathrm{a}}(5)$
\end{tabular}

$\mathrm{pD}_{2}$ indicates the $-\log \mathrm{mol} / \mathrm{l}$ of the required concentration of sodium nitroprusside to reach the half-maximal relaxation. Results are means \pm SEM of the averaged $\mathrm{pD}_{2}$ corresponding to every animal. The respective number of rats is in parenthesis.
${ }^{a} p<0.05$ vs value of the analogous group without aminoguanidine
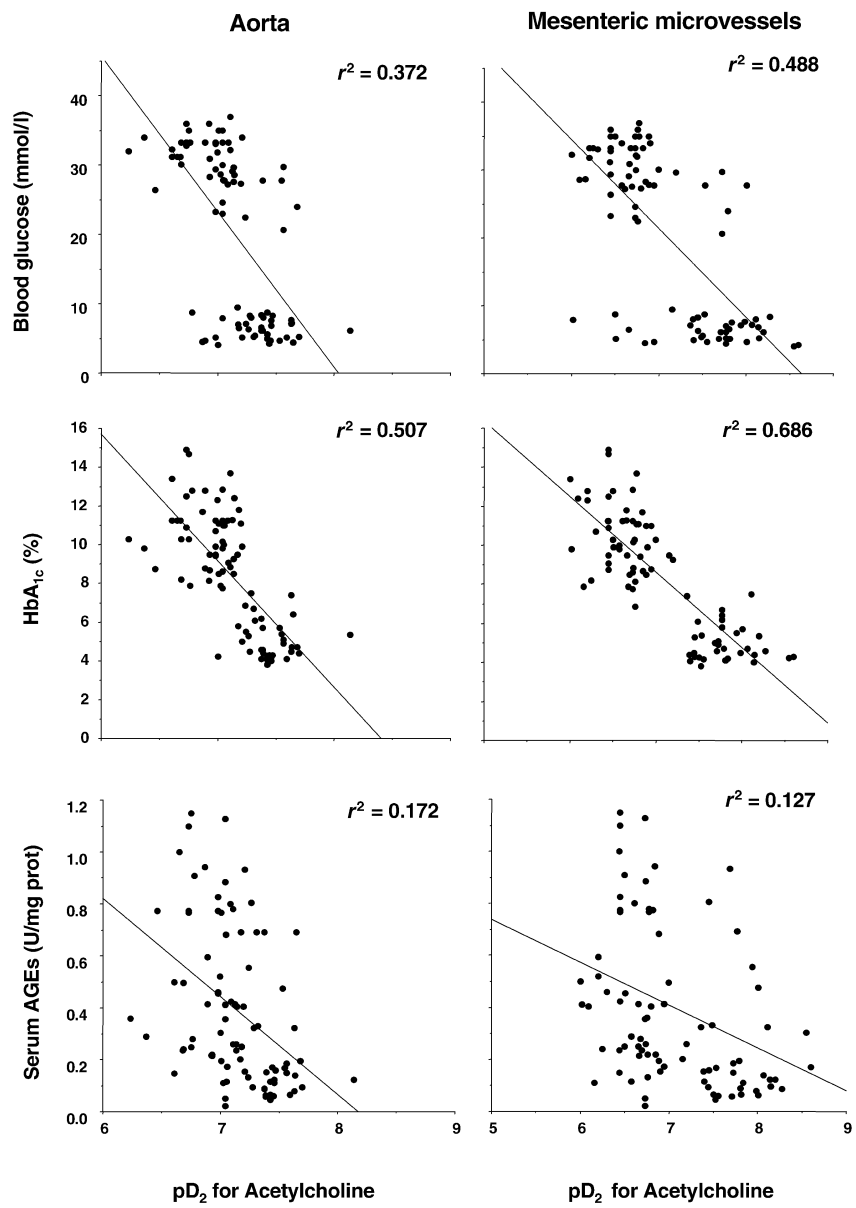

Fig. 6. Correlations between blood glucose, $\mathrm{HbA}_{1 \mathrm{c}}$, and serum concentrations of $\mathrm{AGE}$, and the $\mathrm{pD}_{2}$ values for acetylcholine $(\mathrm{ACh})$ in aortic segments (left) and mesenteric microvessels (right) from the different groups of rats

The endothelium-independent vasodilatatory responses to SNP were tested in de-endothelialized aortic segments as well as in mesenteric microvessels from animals of Week 0, Week 3, Week 6, and Week 9 groups. Vessels from aminoguanidine-treated rats from Week 0, Week 6, and Week 9 groups were also studied. The relaxant responses to SNP were not mod- ified by diabetes or insulin treatment in any studied group (Table 5). However, the relaxations to SNP in mesenteric microvessels were reduced similarly in aminoguanidine-treated rats from all studied groups (Table 5).

Finally, the specific $\mathrm{pD}_{2}$ averaged values for $\mathrm{ACh}$ obtained in the aortic segments and mesenteric microvessels from every studied rat were plotted against blood concentrations of glucose, $\mathrm{HbA}_{1 \mathrm{c}}$, and AGE. In this plot, blood glucose, blood $\mathrm{HbA}_{1 \mathrm{c}}$ and serum $\mathrm{AGE}$ were the independent variables and $\mathrm{pD}_{2}$ the dependent one (Fig. 6). In both types of vessels, there was a higher correlation between the $\mathrm{pD}_{2}$ for $\mathrm{ACh}$ and the blood concentrations of $\mathrm{HbA}_{1 \mathrm{c}}$ than with serum AGE and blood glucose (Fig. 6).

\section{Discussion}

Our study shows the development of endothelial dysfunction and oxidative stress in an early model of Type 1 diabetes mellitus, which closely resembles the modification of the values of early or intermediate glycosylation products during the evolution of the experimental protocol.

The impairment of the endothelium-derived responses have been described in isolated aortic rings $[6,36,42]$ and mesenteric microvessels [36, 43, 44] from streptozotocin-induced diabetic rats, as well as in experiments in vivo [7, 37], which indicate that diabetic endothelial dysfunction is affecting either the conductance and the resistance vasculature. Our results also agree with these previous works, whereas the relaxant responses not mediated by the endothelium were not affected.

An enhancement of oxidative stress in diabetes [8, 9], mainly by an increased generation of superoxide anions $[11,36,42,45]$.is also widely accepted. In the experimental conditions of this study, the preincubation of isolated aortic and mesenteric vascular segments with SOD modify ACh-induced responses only in those groups in which endothelial dysfunction was 
present, but not in the vessels without endothelial dysfunction, supporting a link between oxidative stress and endothelial dysfunction.

We analysed the time course of the alterations of the endothelial function depending on the development of diabetes. Some works in streptozotocininduced diabetic rats do not report any impairment of endothelium-derived relaxations in isolated aortic segments during the first 2 weeks after diabetes was induced $[49,50]$. Using the same diabetic model, other studies on intestinal arterioles [43] or hindquarter haemodynamics [7] indicate endothelial dysfunction 8 to 14 days after streptozotocin administration. We observed statistically significant impairments of ACh-induced relaxations after 2 weeks of diabetes both in mesenteric microvessels and aortic segments, although the alterations were less pronounced in this later vasculature. However, using a similar experimental protocol in isolated aortic segments, another study did not observe alterations in the ACh-induced relaxations after 2 weeks of diabetes [49]. A possible explanation could be that we used older animals, as well as a higher dose of streptozotocin to induce diabetes, which lead to a more aggressive form of diabetes that produces earlier endothelial dysfunction.

Moreover, the discrepancies between studies on the development of diabetic endothelial dysfunction are also probably reflecting differences between conductance and resistance vessels. In quantitative terms, the magnitude of the alterations of endothelium-dependent relaxations in aortic segments was rather modest in our experiments, while the responses observed in mesenteric microvessels were more evident. Furthermore, the recovery of the relaxations by SOD was not the same; the mesenteric microvessels were less sensitive to the action of the enzyme, while the responses in aortic segments were fully recovered in all the cases.

The vascular endothelial dysfunction developed in streptozotocin-induced diabetic rats can be recovered after 8 to 12 weeks of treatment with insulin [51], or with a pancreatic islet transplantation [52]. In these studies, the improvement of endothelial function was accompanied by a parallel improvement in metabolic control, estimated by $\mathrm{HbA}_{1 \mathrm{c}}$ values [52] or by the extinction of glycosuria or ketonuria [51]. In our laboratory, we have shown a close relation between the presence of endothelial dysfunction and the metabolic control of the disease [36, 37]. We confirm that treatment with insulin is able to recover the impairment of the endothelial function produced by diabetes. Thus, 3 weeks of treatment were required to obtain a full recovery of vasodilatatory responses.

The protocol designed for this study established a possible time relation between diabetic endothelial dysfunction and the presence of high glucose and protein glycosylation adducts in blood. Some authors indicate that increased glucose itself is a source of free radicals that leads to endothelium dysfunction $[18,19$, $20,21,22,23,24]$. Our results, however, clearly indicate that high glucose by itself is not directly related to the impairment of endothelium-dependent relaxations. Indeed, 1 week after diabetes induction the blood glucose concentrations reached around $25 \mathrm{mmol} / \mathrm{l}$ and, despite this high glycaemia, AChinduced response was not affected in aorta or in mesenteric microvessels. Furthermore, 1 week after introduction of insulin treatment glycaemia was below normal values but endothelial dysfunction was still present. These results disagree with studies reporting an impairment of endothelial function in vessels from non-diabetic animals incubated in very high concentrations of glucose (20 to $50 \mathrm{mmol} / \mathrm{l})[18,19,20,21$, $22,23,24]$. Nevertheless, in agreement with our findings, other authors have reported a good preservation of endothelial relaxations in short-term diabetes (1 week) induced by streptozotocin in rats [53], or after subacute (1 day) hyperglycaemia in humans [54].

Our data seem to be more consistent with the hypothesis that diabetic endothelial dysfunction is related to processes that require several weeks of evolution, such as protein glycosylation. AGE have been described as a source of free radicals in diabetes [30]. In addition, some reports have indicated the ability of AGE to quench nitric oxide, proposing these compounds as the mediators of defective endothelial relaxations in diabetes $[29,31]$. Our results, however, do not support a very relevant role for AGE as promoters of endothelial dysfunction, at least in a shortterm diabetic model. Thus, the impairment of endothelium-dependent relaxations started 2 weeks after diabetes induction, whereas serum AGE were still low. Furthermore, 3 weeks after insulin treatment there was a clear recovery of ACh-induced vasodilatations, while serum AGE were still high.

To further analyse the role of AGE, additional groups of rats were treated with aminoguanidine in drinking water. This drug seems to inhibit the formation of AGE mainly by reacting with Amadori-derived fragmentation adducts in solution [52]. Therefore, the formation of Amadori adducts during protein glycosylation is supposed to be unaffected by aminoguanidine $[31,55,56]$. The administration of aminoguanidine during one month to diabetic patients reduces circulating AGE, without altering $\mathrm{HbA}_{1 \mathrm{c}}$ values $[32,56]$. Several studies indicate that treatment of streptozotocininduced diabetic rats with aminoguanidine prevents the development of diabetic retinopathy [57] and cardiomyopathy [58], as well as the impairment of endothelium-dependent relaxations to ACh [29, 59]. Some investigators, however, suggest that the effects of aminoguanidine could reflect inhibition of nitric oxide synthases rather than preventing AGE formation [60]. In our experimental conditions, aminoguanidine treatment did not alter ACh-evoked relaxations in vessels from non-diabetic rats, indicating that endothelial pro- 
duction of nitric oxide is not inhibited. However, aminoguanidine treatment reduced the SNP-induced vasodilatations in mesenteric microvessels, suggesting it could interfere with the vasoactive responses, at least in the resistance vasculature. In diabetic animals, aminoguanidine treatment did not restore the impaired ACh-induced responses, and there was a decrease of endothelial relaxation that was recovered only after 3 weeks of insulin treatment. Aminoguanidine clearly reduce serum AGE in all diabetic groups of rats, suggesting they are not related to the induction of endothelial alterations.

The lack of a relevant role for circulating AGE as mediators of endothelial dysfunction can be a consequence of the short duration of the disease in this experimental model. The evolution of streptozotocininduced diabetes is not longer than 9 weeks, which is a rather acute model of the disease. In a seminal work [29], diabetic endothelial dysfunction was studied during 1-year diabetes evolution, while aminoguanidine treatment was analysed for a 2 -month period. Tissue AGE seem to be more important than circulating AGE in the development of diabetic vascular complications [31]. During the 6 weeks of untreated diabetes designed in this experimental protocol, either with or without aminoguanidine, we did not find changes in vascular tissue AGE, suggesting that the possible enhancement of these compounds in the vascular wall would require diabetes to be further developed. Some works indicate that renal and vascular tissue AGE can increase even after 5 weeks of diabetes [61, 62]. However, a recent review [63] states the difficulties to compare AGE determinations between laboratories, indicating that the time required for these compounds to produce pathological changes is usually of several months.

As an alternative and/or complementary hypothesis, we have proposed that endothelial dysfunction during the first weeks or months of diabetes evolution could be related with the presence of early and/or intermediate glycosylation Amadori adducts [33, 34, $35]$. We found a close correlation between the blood concentrations of $\mathrm{HbA}_{1 \mathrm{c}}$, a well known Amadori adduct [32], and the development of endothelial dysfunction in streptozotocin-induced diabetic rats [36, 37]. In agreement with this, other authors provide evidence that early glycosylation Amadori-modified proteins, namely Amadori albumin, correlate with markers of diabetic endothelial dysfunction [38]. Thus, Amadori albumin can be associated with diabetic nephropathy, and it can be localised in retinal capillaries from diabetic patients [38]. Furthermore, all these studies are also consistent with the idea that oxidative stress observed in patients or diabetic animals is directly related to the metabolic control of the disease [33, 34, 35, 36, 37, 38, 46, 47, 48].

We further confirm the correlation between the blood concentrations of $\mathrm{HbA}_{1 \mathrm{c}}$ and the presence of en- dothelial dysfunction. In both aortic and mesenteric vessels, the impairment and the recovery of endothelial function occurred when the $\mathrm{HbA}_{1 \mathrm{c}}$ values increased or decreased, respectively. There was a clear correlation between endothelial dysfunction and the blood concentrations of $\mathrm{HbA}_{1 \mathrm{c}}$, whereas the correlation with AGE and blood glucose was low. Therefore, it seems that the enhancement of Amadori adducts is the factor offering a better relation with the development of endothelium impairment, at least in this experimental model of diabetes.

There are clinical data consistent with our experimental results. Oxidative stress is an event that can be observed very early in children and adolescents with Type 1 diabetes mellitus [64]. In addition, the progression of microalbuminuria to proteinuria in a large group of Type 1 diabetic patients has been analysed [65]. This study concluded that the risk of albuminuria progression can be reduced by improving glycaemic control only if $\mathrm{HbA}_{1 \mathrm{c}}$ is maintained below $8.5 \%$. Moreover, below that value, the risk declines as the $\mathrm{HbA}_{1 \mathrm{c}}$ value decreases; in addition, the range between $7 \%$ and $8.5 \%$ is critical for the development of proteinuria [65]. Of note, these percentages of $\mathrm{HbA}_{1 \mathrm{c}}$ are the same that are found required to induce superoxide anion-mediated endothelial dysfunction in human micovessels [35], as in streptozotocin-induced diabetic rats to develop endothelial dysfunction [36, 37] and similar to those obtained in our experiments. Furthermore, in agreement with all these data, recent epidemiological studies indicate that $\mathrm{HbA}_{1 \mathrm{c}}$ is an important risk factor for cardiovascular mortality in the general population [66].

In conclusion, we show that circulating concentrations of $\mathrm{HbA}_{1 \mathrm{c}}$ resembles the time course of diabetic endothelial dysfunction. Although we do not provide definitive evidence for a causal link between this Amadori adduct and endothelium impairment, these results support the proposal of a relevant role for this and other early and intermediate products of protein glycosylation in the development of diabetic vasculopathy.

Acknowledgements. We wish to thank to M.C. FernándezCriado and to J.M. Badajoz-Martínez for animal care. This work was supported by grants fom Ministerio de Ciencia y Tecnología (SAF2001-1328), Comunidad Autónoma de Madrid (08.4/0030/2001 2) and FIS (99/0246).

\section{References}

1. Calver A, Collier J, Vallance P (1992) Inhibition and stimulation of nitric oxide synthesis in the human forearm arterial bed of patients with insulin-dependent diabetes. J Clin Invest 90:2548-2554

2. McVeigh GE, Brennan GM, Jonhson GD et al. (1992) Impaired endothelium-dependent and independent vasodilation in patients with Type II (non-insulin-dependent) diabetes mellitus. Diabetologia 35:771-776 
3. Johnstone MT, Creager SJ, Scales KM, Cusco JA, Lee BK, Creager MA (1993) Impaired endothelium-dependent vasodilation in patients with insulin-dependent diabetes mellitus. Circulation 88:2510-2516

4. Fortes ZB, Leme JG, Scivoletto R (1983) Vascular reactivity in diabetes mellitus: role of the endothelial cells. $\mathrm{Br}$ J Pharmacol 79:771-781

5. Durante W, Sen AK, Sunahara FA (1988) Impairment of endothelium-dependent relaxation in aortae from spontaneously diabetic rats. Br J Pharmacol 94:463-468

6. Kamata K, Miyata N, Kasuya Y (1989) Impairment of endothelium-dependent relaxation and changes in levels of cyclic GMP in aorta from streptozotocin-induced diabetic rats. Br J Pharmacol 97:614-618

7. Kiff RJ, Gardiner SM, Compton AM, Bennet T (1991) Selective impairment of hindquarters vasodilator responses to bradykinin in conscious Wistar rats with streptozotocin-induced diabetes mellitus. $\mathrm{Br} \mathrm{J}$ Pharmacol 103: 1357-1362

8. Baynes JW (1991) Role of oxidative stress in development of complications in diabetes. Diabetes 40:405-412

9. Ceriello A, Quatraro A, Giugliano D (1993) Diabetes mellitus and hypertension: the possible role of hyperglycaemia through oxidative stress. Diabetologia 36:265-266

10. Young IS, Tate S, Lightbody JH, Mcmaster D, Trimble ER (1995) The effects of desferoxamine and ascorbate on oxidative stress in the streptozotocin diabetic rat. Free Radic Biol Med 18:833-840

11. Chang KC, Chung SY, Chong WS et al. (1993) Possible superoxide radical-induced alteration of vascular reactivity in aortas from streptozotocin-treated rats. J Pharmacol Exp Ther 266:992-1000

12. Tesfamariam B (1994) Free radicals in diabetic endothelial cell dysfunction. Free Radic Biol Med 16:383-391

13. Giugliano D, Ceriello A, Paolisso G (1996) Oxidative stress and diabetic vascular complications. Diabetes Care 19:257-267

14. Ceriello A, dello Russo P, Amstad P, Cerutti P (1996) High glucose induced antioxidant enzymes in human endothelial cells in culture. Evidence linking hyperglycemia and oxidative stress. Diabetes 45:471-477

15. Diabetes Control and Complications Trial Research Group (DCCT) (1993) The effect of intensive treatment of diabetes on the development and progression of long-term complications in insulin-dependent diabetes mellitus. N Engl J Med 329:977-986

16. Viberti G (1995) A glycemic threshold for diabetic complications? N Engl J Med 332:1293-1294

17. Hanssen KF (1997) Blood glucose control and microvascular and macrovascular complications in diabetes. Diabetes 46[Suppl 29]:S101-S103

18. Tesfamariam B, Brown ML, Cohen RA (1991) Elevated glucose impairs endothelium-dependent relaxation by activating protein kinase C. J Clin Invest 87:1643-148

19. Tesfamariam B, Brown ML, Cohen RA (1992) Aldose reductase and myo-inositol in endothelial cell dysfunction caused by elevated glucose. J Pharmacol Exp Ther 263:153-157

20. Tesfamarian B, Cohen RA (1992) Free radicals mediate endothelial cell dysfunction caused by elevated glucose. Am J Physiol 263: H321-H326

21. Taylor PD, Poston L (1994) The effect of hyperglycaemia on function of rat isolated mesenteric artery. Br J Pharmacol 113:801-808

22. Félétou M, Rasetti C, Duhault J (1994) Magnesium modulates endothelial dysfunction produced by elevated glucose incubation. J Cardiovasc Pharmacol 24:470-478
23. Pieper GM, Meier DA, Hager SR (1995) Endothelial dysfunction in a model of hyperglycemia and hyperinsulinemia. Am J Physiol 269:H845-H850

24. Dorigo P, Fraccarollo D, Santostasi G, Maragno I (1997) Impairment of endothelium-dependent but not of endothelium-independent dilatation in guinea-pig aorta rings incubated in the presence of elevated glucose. Br J Pharmacol 121:972-976

25. Hopfner RL, Gopalakrishnan V (1999) Endothelin: emerging role in diabetic vascular commplications. Diabetologia 42:1383-1394

26. De Vriese AS, Verbeuren TJ, Van de Voorde J, Lameire NH, Vanhoutte PM (2000) Endothelial dysfunction in diabetes. Br J Pharmacol 130:963-974

27. García Soriano F, Virág L, Japtag P et al. (2001) Diabetic endothelial dysfunction: the role of poly(ADP-ribose) polymerase activation. Nat Med 7:108-113

28. Hink U, Li H, Mollnan H et al. (2001) Mechanisms underlying endothelial dysfunction in diabetes mellitus. Circ Res 88:E14-E22

29. Bucala R, Tracey KJ, Cerami A (1991) Advanced glycosylation products quench nitric oxide and mediate defective endothelium-dependent vasodilation in experimental diabetes. J Clin Invest 87:432-438

30. Wautier JL, Wautier MP, Schmidt AM et al. (1994) Advanced glycation end products (AGEs) on the surface of diabetic erythrocytes bind to the vessel wall via a specific receptor inducing oxidant stress in the vasculature: a link between surface-associated AGEs and diabetic complications. Proc Natl Acad Sci USA 91:7742-7746

31. Vlassara H (1997) Recent progress in advanced glycation end products and diabetic complications. Diabetes 46[Suppl 2]:S19-S25

32. Makita Z, Vlassara H, Rayfield E et al. (1992) Hemoglobin-AGE: a circulating marker of advanced glycosylation. Science 258:651-653

33. Rodríguez-Mañas L, Arribas S, Girón C, Villamor J, Sánchez-Ferrer CF, Marín J (1993) Interference of glycosylated human hemoglobin with endothelium-dependent responses. Circulation 88:2111-2116

34. Angulo J, Sánchez-Ferrer CF, Peiró C, Marín J, RodríguezMañas L (1996) Impairment of endothelium-dependent relaxation by increasing percentages of glycosylated human hemoglobin. Possible mechanisms involved. Hypertension 28:583-592

35. Vallejo S, Angulo J, Peiró C et al. (2000) Highly glycosylated oxyhemoglobin impairs nitric oxide relaxations in human mesenteric microvessels. Diabetologia 43:83-90

36. Rodríguez-Mañas L, Angulo J, Peiró C et al. (1998) Endothelial dysfunction and metabolic control in streptozotocininduced diabetic rats. Br J Pharmacol 123:1495-1502

37. Angulo J,Rodríguez-Mañas L, Peiró C, Neira M, Marín J, Sánchez-Ferrer CF (1998) Impairment of nitric oxide-mediated relaxations in anaesthetized autoperfused streptozotocin-induced diabetic rats. Naunyn Schmiedebergs Arc Pharmaco358:529-537

38. Schalkwijk CG, Ligtvoet N, Twaalfhoven H et al. (1999) Amadori albumin in Type 1 diabetic patients. Correlation with markers of endothelial function, association with diabetic nephropathy, and localization in retinal capillaries. Diabetes 48:2446-2453

39. Karl J, Burns G, Engel WD et al. (1993) Development and standardization of a new immunoturbidimetric HbA1c assay. Clin Lab 39:991-996

40. Makita Z, Vlassara H, Cerami A, Bucala R (1992) Immunochemical detection of advanced glycosylation end products in vivo. J Biol Chem 267:5133-5138 
41. Mulvany MJ, Halpern W (1977) Contractile properties of small arterial resistance arteries in spontaneously hypertensive and normotensive rats. Circ Res 41:19-26

42. Hattori Y, Kawasaki H, Abe K, Kanno M (1991) Superoxide dismutase recovers altered endothelium-dependent relaxation in diabetic rat aorta. Am J Physiol 261: H1086-H1094

43. Lash JM, Bohlen HG (1991) Structural and functional origins of supressed acetylcholine vasodilation in diabetic rat intestinal arterioles. Circ Res 69:1259-1268

44. Taylor PD, McCarthy AL, Thomas CR, Poston L (1992) Endothelium-dependent relaxation and noradrenaline sensitivity in mesenteric resistance arteries of streptozotocininduced diabetic rats. Br J Pharmacol 107:393-399

45. Langenstroer P, Pieper GM (1992) Regulation of spontaneous EDRF release in diabetic rat aorta by oxygen free radicals. Am J Physiol 263: H257-H265

46. Diederich D, Skopec J, Diederich A, Dai FX (1994) Endothelial dysfunction in mesenteric resistance arteries of diabetic rats: role of free radicals. Am J Physiol 266: H1153-H1161

47. Ceriello A, Giugliano D, Quatraro A, Dello Russo P, Lefebvre PJ (1991) Metabolic control may influence the increased superoxide generation in diabetic serum. Diabet Med 8:540-542

48. Pieper GM, Jordan M, Dondlinger LA, Adams MB, Roza AM (1995) Peroxidative stress in diabetic blood vessels. Reversal by pancreatic islet transplantation. Diabetes 44:884-889

49. Pieper GM (1999) Enhanced, unaltered and impaired nitric-oxide mediated endothelium-dependent relaxation in experimental diabetes: importance of disease duration. Diabetologia 42:204-213

50. Hopfner RL, McNeill JR, Gopalakrishnan V (1999) Plasma endothelin levels and vascular responses at different temporal stages of streptozotocin diabetes. Eur J Pharmacol 373:221-227

51. Taylor PD, Oon BB, Thomas CR, Poston L (1994) Prevention by insulin treatment of endothelial dysfunction but not enhanced noradrenaline-induced contractility in mesenteric resistance arteries from streptozotocin-induced diabetic rats. Br J Pharmacol 111:35-41

52. Pieper GM, Jordan M, Adams MB, Roza AM (1995) Syngeneic pancreatic islet transplantation reverses endothelial dysfunction in experimental diabetes. Diabetes 44:1106-1115

53. Brands MW, Fitzgerald SM (1998) Acute endothelium-mediated vasodilation is not impaired at the onset of diabetes. Hypertension 32:541-547
54. Houben AJHM, Schaper NC, De Haan CHA et al. (1996) Local 24-h hyperglycemia does not affect endotheliumdependent or -independent vasoreactivity in humans. Am J Physiol 270:H2014-H2020

55. Edelstein D, Brownlee M (1992) Mechanistic studies of advanced glycosylation end product inhibition by aminoguanidine. Diabetes 41:26-29

56. Soulis T, Cooper ME, Sastra S et al. (1997) Relative contribution of advanced glycation and nitric oxide synthase inhibition to aminoguanidine-mediated renoprotection in diabetic rats. Diabetologia 40:1141-1151

57. Hammes HP, Martin S, Federlin K, Geisen K, Brownlee M (1991) Aminoguanidine treatment inhibits the development of experimental diabetic retinopathy. Proc Natl Acad Sci USA 88:11555-11558

58. Norton GR, Candy G, Woodiwiss A (1996) Aminoguanidine prevents the decreased myocardial compliance produced by streptozotocin-induced diabetes mellitus in rats. Circulation 93:1905-1912

59. Archibald V, Cotter MA, Keegan A, Cameron NE (1996) Contraction and relaxation of aortas from diabetic rats: effects or chronic anti-oxidant and aminoguanidine treatments. Naunyn-Schmiedeberg's Arch Pharmacol 353:584-591

60. Tilton RG, Chang K, Hasan KS et al. (1993) Prevention of diabetic vascular dysfunction by guanidines. Inhibition of nitric oxide synthase versus advanced glycation end-product formation. Diabetes 42:221-232

61. Nakayama H, Tanade S, Mitsuhashi T et al. (1991) Characterisation of antibody to advanced glycated end-products of protein. J Immunol Methods 140:119-125

62. Baynes JW, Thorpe SR (1999) Role of oxidative stress in diabetic complications. A new perspective onn an old paradigm. Diabetes 48:1-9

63. Singh R, Barden A, Mori T, Beilin L (2001) Advanced glycation end-products: a review. Diabetologia 44:129-146

64. Domínguez C, Ruiz E, Gussinye M, Carrascosa A (1998) Oxidative stress at onset and in early stages of type 1 diabetes in children and adolescents. Diabetes Care 21:1736-1742

65. Warram JH, Scott LJ, Hanna LS et al.(2000) Progression of microalbuminuria to proteinuria in Type 1 diabetes. Nonlinear relationship with hyperglycemia. Diabetes 49: 94-100

66. Khaw KT, Warehan N, Luber R et al. (2001) Glycated haemoglobin, diabetes and mortality in men in Norfolk cohort of European Prospective Investigation of Cancer and Nutrition (Epic-Norfolk). BMJ 332:1-6 